\title{
Literatura e conhecimento sociológico
}

\section{Cinara L. Rosenfield* Jalcione Almeida*}

ociologias traz, neste número, a discussão acerca da relação entre Sociologia e Literatura, em dossiê organizado por Ana Lúcia Teixeira. A revista, anteriormente, já havia publicado outro dossiê com uma aproximação ao tema, em seu trigésimo quarto número, intitulado "Figurações da violência", em que foram abordadas as representações coletivas sobre a violência na modernidade com base em uma sociologia do romance policial e do romance da violência. O presente número, contudo, inova ao trazer a literatura simultaneamente como objeto e como ator do conhecimento sociológico.

Em sentido ampliado, de acordo com Araújo Neto (2007), a ideia de que uma obra literária constitui certo modo de representação da realidade tem aceitação entre teóricos renomados da literatura, tais como René Wellek, Austin Warren, Erich Auerbach, Lucien Goldmann, Afrânio Coutinho, Antonio Candido, entre outros. ${ }^{1}$ Segundo aquele autor, ampliando-se as

\footnotetext{
*Universidade Federal do Rio Grande do Sul. Porto Alegre, RS, Brasil

${ }^{1}$ Para um rápido panorama histórico dos principais vetores teórico-metodológicos desenvolvidos no que é usualmente chamado de "sociologia da literatura", além de Araújo Neto (2007), ver também Alves, Leão e Teixeira (2018b).
} 
indagações em direção às "relações entre literatura e sociedade, apresentase-nos a necessidade de uma reflexão sobre como os métodos sociológicos de abordagem do texto literário, ou mais especificamente a chamada sociologia da literatura, entenderiam o problema da representação da realidade pela literatura" (Araújo Neto, 2007, p. 16).

Segundo sua organizadora, "a proposta deste dossiê envolve uma dupla entrada analítica: de um lado, tratou-se de redesenhar a literatura como objeto particular no conjunto dos objetos estéticos, de forma a reivindicar um aparato conceitual específico, que não se confunde com aqueles dedicados à análise de outras formas de arte; de outro, tratou-se de recuperar a literatura como intérprete do mundo social, dotada da capacidade de formular questões que interessam à sociologia, ainda que o faça por meio de propriedades formais diversas" (Teixeira, 2018, p. 22).

Os autores que integram o dossiê propõem diferentes abordagens para pensar a articulação entre literatura e sociologia: seja a partir da leitura, ou seja, da relação estabelecida entre o autor e o leitor através do texto, seja pela concepção da literatura como possíveis caminhos perceptivos para o aprofundamento do conhecimento da sociedade, ou ainda pelo seu valor estético na relação entre forma ou conteúdo, além de discutir seu potencial revolucionário ao propor outros mundos alternativos. Cabe assinalar, no entanto, que há questionamentos de fundo que perpassam todas essas possibilidades: teria a literatura um valor epistêmico per se ao mobilizar toda a sua especificidade em construir um aparato próprio de compreensão do mundo social, ou seu valor repousaria na tradução do mundo ao formular uma legibilidade a problemas sociais emergentes, de maneira a configurar uma relação específica com a sociologia? A literatura seria um valor estético em si mesmo e, assim, capaz de construção de um imaginário próprio que não se pode reduzir à tradução do social, ou seria um objeto sociológico, ao fornecer os elementos que permitem estabelecer relações entre o texto literário e o momento de sua produção, de maneira a fazer emergirem aspectos do contexto histórico, social e político? 
A intenção do dossiê aponta para uma convergência de ambas as tendências, muito embora seus autores oscilem entre elas. Nesse movimento, o que se pretende enfatizar "é a possibilidade de uma atuação política que se decide esteticamente, perspectiva metodológica que envolve, a um só tempo, o reconhecimento da dimensão epistêmica da literatura - porque entende que, por meio dela, se processa uma leitura do mundo social - e da atuação política de seu autor - já que é o próprio texto que surge como ferramenta de interferência nesse mundo" (Teixeira, 2018, p. 27).

Tomada em seu sentido mais literal e restritivo, a sociologia da literatura pode ser considerada uma especialidade da sociologia, consagrada a analisar as obras a partir de um eixo interpretativo que transcende a configuração linguística e discursiva. Assim, ela se dedicaria a buscar os fatores externos à obra, os condicionantes de sua estruturação, de maneira a delinear as condições sociais de criação da obra literária. Já a crítica literária, em seara própria, buscaria a organização interna à obra, cabendo ao social a matéria-prima da força criativa. Ora, a proposta aqui é também transcender, mas no sentido de transcender a sociologia da literatura - a crítica literária não estaria nesse momento em questão - e consagrar-se a refletir sobre a relação entre literatura e conhecimento sociológico. Não se trata de fazer o paralelo entre o trabalho literário e a realidade exterior, mas fazer emergir a complexidade das relações dentro (a obra) e fora (o social), do interno e do externo, seguindo no sentido apontado por Antonio Candido no qual "o externo [no caso, o social] importa, não como causa, nem como significado, mas como elemento que desempenha um certo papel na constituição da estrutura, tornando-se assim, interno" (Candido, 2000, p.14).

Nesse sentido, sociologia e literatura possuem íntimas e complexas relações, como os artigos deste dossiê tão bem demonstram.

Fora do dossiê, na seção Artigos, os pesquisadores portugueses João Arriscado Nunes, Daniel Neves da Costa, António Carvalho e Ana Raquel Matos, do Centro de Estudos Sociais da Universidade de Coimbra, analisam dois estudos de caso - grupos de discussão sobre nanotecnologias em Coimbra e Conselhos de Saúde em Belo Horizonte - e propõem uma reflexão 
sobre as questões políticas e metodológicas relacionadas à concepção e implementação de procedimentos participativos. Os dois estudos de caso ilustram como os procedimentos participativos geram novas capacidades epistêmicas, retóricas e normativas associadas à habilitação e subjetivação dos participantes. Já Marcos Flávio Rolim, do Tribunal de Contas do Estado do Rio Grande do Sul, e Daiana Hermann, da Universidade Federal do Rio Grande do Sul, analisam os resultados colhidos em pesquisa de vitimização realizada em Porto Alegre, acerca da percepção dos residentes sobre o trabalho da Polícia Militar e da Polícia Civil. A análise dos dados evidencia baixas taxas de confiança para ambas as polícias estaduais. Os autores levantam diretrizes que podem auxiliar no processo de definição de políticas específicas para reversão desse quadro. Por sua vez, Alyson Thiago Fernandes Freire, do Instituto Federal de Educação, Ciência e Tecnologia do Rio Grande do Norte, explora e discute o "ponto de vista trágico" - ou a visão trágica da existência humana - no pensamento sociológico de Georg Simmel e Max Weber, a fim de identificar a atuação de uma sensibilidade trágica na abordagem dos processos conformadores da cultura moderna. $\mathrm{E}$ ainda, o ensaio de Jair Araújo de Lima e Rita de Cássia Fazzi, da Pontifícia Universidade Católica de Minas Gerais, explora o referencial teórico que fundamenta uma concepção do sujeito como agente reflexivo e plural. A partir de uma discussão bibliográfica, tomam aspectos das pesquisas de vários autores como evidência de que - quaisquer que sejam as linhas teóricas dos autores citados - vários estudiosos têm apontado para a reflexividade e pluralidade constitutivas do ator social.

Na seção Interfaces, José Marcos Froehlich, da Universidade Federal de Santa Maria, e Mauro Barcellos Sopeña, da Universidade Federal do Pampa, estabelecem a relação entre a noção de desenvolvimento e a de felicidade. Empreendem uma análise de tal associação a partir da interpretação freudiana sobre a relação entre indivíduo e sociedade, principalmente aquela apresentada na obra clássica "O mal-estar na civilização". Trata-se de explorar o dilema entre psiquismo humano e cultura na construção de indicadores de desenvolvimento e felicidade. 
Por último, na seção Resenhas, Léo Peixoto Rodrigues e Everton Garcia da Costa, da Universidade Federal de Pelotas, destacam a publicação de "Sistemas sociais: esboço para uma teoria geral", de Niklas Luhmann, uma das principais obras do autor, publicada originalmente em 1984, de inegável importância não apenas para a sociologia, mas para o vasto campo das ciências humanas e sociais, no qual raras obras do autor encontram-se traduzidas para o português. Outra resenha, de Rodrigo Foresta Wolffenbuttel, da Universidade Federal do Rio Grande do Sul, explora os principais aspectos da obra "Sociologia dell'innovazione economica", do sociólogo italiano Francesco Ramella. Obra voltada para dimensões específicas da inovação, o livro apresenta as mais importantes contribuições da sociologia para o campo de pesquisa dos Innovation Studies. Para tanto, a obra recupera as contribuições sociológicas desde os clássicos da disciplina, até pesquisas atuais sobre o tema, de forma a definir o conceito de inovação e justificar a relevância da abordagem sociológica para o campo específico, mas também para a teoria sociológica em geral.

Tenham todos uma ótima leitura.

\section{Referências}

1. ALVES, Paulo C.; LEÃO, Andréa B.; TEIXEIRA, Ana Lúcia. Sociologia da Literatura: tradições e tendências contemporâneas. Revista Brasileira de Sociologia, v. 6, n. 12, p. 222-241, jan-abr, 2018.

2. ARAÚJO NETO, Miguel L. A sociologia da literatura: origens e questionamentos. Entrelaces, p. 15-20, ago. 2007.

3. CANDIDO, Antonio. Literatura e Sociedade: estudos de teoria e história literária. Rio de Janeiro, São Paulo: Publifolha, 2000.

4. TEIXEIRA, Ana Lúcia. Literatura e sociologia: relações de mútua incitação. Sociologias, v. 20, n. 48, pp. 16-29, 2018. http://dx.doi.org/10.1590/15174522020004801 